\title{
The influence of the specific growth rate on the lipid composition of Sulfolobus acidocaldarius
}

\author{
Julian Quehenberger ${ }^{1} \cdot$ Ernst Pittenauer $^{2} \cdot$ Günter Allmaier $^{2} \cdot$ Oliver Spadiut $^{1}$
}

Received: 24 October 2019 / Accepted: 9 March 2020 / Published online: 21 March 2020

(c) The Author(s) 2020

\begin{abstract}
Archaeal lipids are constituted of two isoprenoid chains connected via ether bonds to glycerol in the $s n-2,3$ position. Due to these unique properties archaeal lipids are significantly more stable against high temperature, low $\mathrm{pH}$, oxidation and enzymatic degradation than conventional lipids. Additionally, in members of the phylum Crenarchaeota condensation of two (monopolar) archaeal diether lipids to a single (bipolar) tetraether lipid as well as formation of cyclopentane rings in the isoprenoid core strongly reduce permeability of the crenarchaeal membranes. In this work we show that the Crenarchaeum Sulfolobus acidocaldarius changes its lipid composition as reaction to a shift in growth rate caused by nutrient limitation. We thereby identified a novel influencing factor for the lipid composition of S. acidocaldarius and were able to determine the effect of this factor on the lipid composition by using MALDI-MS for the semi-quantification of an archaeal lipidome: a shift in the specific growth rate during a controlled continuous cultivation of $S$. acidocaldarius from 0.011 to $0.035 \mathrm{~h}^{-1}$ led to a change in the ratio of diether to tetraether lipids from 1:3 to 1:5 and a decrease of the average number of cyclopentane rings from 5.1 to 4.6 .
\end{abstract}

Keywords Sulfolobus acidocaldarius $\cdot$ Diether lipids $\cdot$ Tetraether lipids $\cdot$ Specific growth rate $\cdot$ Cyclopentane rings

\section{Introduction}

Although today Archaea are known to ubiquitously thrive in habitats all over the world, they have long been considered classical model organisms for "extreme" environments. This historic misconception might be a reason for the extensive interest in the archaeal membrane composition from very early on in archaeal research, as the membrane is the main

Communicated by S. Albers.

Electronic supplementary material The online version of this article (https://doi.org/10.1007/s00792-020-01165-1) contains supplementary material, which is available to authorized users.

Oliver Spadiut

oliver.spadiut@tuwien.ac.at

1 Research Division Biochemical Engineering, Faculty of Technical Chemistry, Institute of Chemical, Environmental and Bioscience Engineering, TU Wien, Vienna, Austria

2 Research Group for Mass Spectrometric Bio and Polymer Analytics, Faculty of Technical Chemistry, Institute of Chemical Technologies and Analytics, TU Wien, Vienna, Austria protective barrier of a cell against its surroundings (van de Vossenberg et al. 1998). Indeed, the fundamental difference in membrane architecture and chemistry of membrane lipids between Archaea on the one hand and Bacteria and Eukarya on the other hand is a characteristic feature of distinction and probably the most obvious biochemical trait unique to the archaeal Domain. Archaeal membranes are composed of ether lipids: glycerol-1-phosphate backbones are linked via ether bonds to two isoprenoid chains (Koga and Morii 2007; Jain et al. 2014). Two main classes of these ether lipids dominate the archaeal lipid spectrum: polar diether lipids (DELs) commonly containing 20 or 25 carbon atoms per isoprenoid chain and monolayer forming bipolar tetraether lipids (TELs) commonly containing 40 carbon atoms per isoprenoid chain. The biosynthesis of DELs via the mevalonate pathway is well understood (Jain et al. 2014), while the mechanism of TEL synthesis is not resolved yet. Head-to-head condensation of two DELs and consecutive introduction of cyclic ring structures is the most popular hypothesis (Jain et al. 2014), while also a more complex, stepwise pathway has been proposed (Villanueva et al. 2014). Independent of the actual mechanism, two proteins, Saci_0421 and Saci_1201, responsible for the formation of 
cyclopentane in Sulfolobus acidocaldarius have been identified by Guan et al. (2017).

Described variations of the two main lipid structures include the following: (1) differences in head groups-a range of polar compounds and sugar residues were observed as head groups [e.g., phospholipids containing glycerol, serine, ethanolamine, myo-inositol or in case of glycolipids: glucose, galactose, mannose, gulose, $\mathrm{N}$-acetylglucosamine or combinations thereof (Shimada et al. 2008; Oger and Cario 2013)]; (2) chain length of the isoprenoid core (e.g., Matsuno et al. 2009); (3) unsaturation (Dawson et al. 2012); (4) methylation of the isoprenoid chain (Knappy et al. 2009; Yoshinaga et al. 2015); (5) linkage between the isoprenoid chains (Morii et al. 1998); and (6) introduction of ring systems-generally ranging 1-8 cyclopentane rings (De Rosa and Gambacorta 1988; Lai et al. 2008; Jensen et al. 2015a), but also the incorporation of a hexane ring has been reported in multiple crenarchaeal species (Damsté et al. 2002, 2018).

As of now, most studies investigated the effect of growth temperature on the lipid composition. In general, Archaea react to increased temperatures with condensation of two monopolar to one single membrane-spanning bipolar lipid (e.g., Lai et al. 2008; Matsuno et al. 2009). As a further adaption strategy Crenarchaeota incorporate higher numbers of cyclopentane rings in their monopolar lipids (Chong 2010; Jensen et al. 2015b). Although no general correlation between the temperature optimum of a Crenarchaeum and the number of cyclopentane rings can be made, it is evident that a rise of the growth temperature stimulates the organisms to increase the number of rings in their lipids. In other archaeal phyla, in addition to the temperature, the influence of hydrostatic pressure, $\mathrm{pH}$ and salinity were investigated (e.g., Kaneshiro and Clark 1995; Shimada et al. 2008; Dawson et al. 2012). Clearly, when investigating the adaption of the lipid composition the focus in the scientific literature lies (1) on variations of these external, environmental factors (temperature, hydrostatic pressure, $\mathrm{pH}$ and salinity) and (2) on the comparison of exponential growth (log phase) vs. stationary phase which was done by many different groups with different organisms (e.g., Elling et al. 2014; Jensen et al. 2015b; Kramer and Sauer 1991; Matsuno et al. 2009; Meador et al. 2014; Morii and Koga 1993). A third factor with supposedly high potential to impact the lipid composition is (3) the level of energy and nutrient supply of the culture. A study performed by Bischof et al. (2019) showed that complete starvation of the uracil auxotrophic strain $S$. acidocaldarius MW001 resulted in a higher number of cyclopentane rings compared to nutrient rich conditions.

A factor that has never been tested for its influence on the lipid composition of Archaea is the specific growth rate $(\mu)$. In this study, we cultivated S. acidocaldarius DSM639, a member of the phylum Crenarchaeota and widely popular archaeal model organism, under nutrient limited conditions.
We maintained two different substrate uptake rates $\left(q_{\mathrm{s}}\right)$, and consequently two distinct $\mu$ s, by employing different feeding rates during a continuous cultivation. Our goal was to determine the ratio of mono- to bipolar lipids (DEL:TEL ratio) and the number of cyclopentane rings in the isoprenoid lipid core in dependence of $\mu$ under controlled nutrient limiting conditions. Thereby, we aim to test the hypothesis that rather than a different growth phase, like already observed in previous studies, a change in the specific growth rate is the direct cause for changes in the lipid pattern of $S$. acidocaldarius.

\section{Materials and methods}

\section{Cultivation and bioreactor setup}

S. acidocaldarius DSM 639 was cultivated in a 3.6-L glass bioreactor (Labfors 3, Infors, Germany) implemented as continuous stirred-tank reactor (CSTR) with $2 \mathrm{~L}$ working volume. The preculture was grown in a $100-\mathrm{mL}$ shake flask at $75^{\circ} \mathrm{C}$ and $100 \mathrm{rpm}$ in $50 \mathrm{~mL}$ VD-Medium (Quehenberger et al. 2019) containing $1.75 \mathrm{~g} / \mathrm{L}$ Na-glutamate (MSG), $3 \mathrm{~g} / \mathrm{L}$ D-glucose and $0.5 \mathrm{~g} / \mathrm{L}$ citric acid, adjusted to $\mathrm{pH} 3.0$ with sulfuric acid. At an $\mathrm{OD}_{600}$ of 0.75 the preculture was transferred aseptically to the culture vessel yielding an initial $\mathrm{OD}_{600}$ of 0.023 and a total starting volume for the initial batch phase of $1.5 \mathrm{~L}$, containing $2 \mathrm{~g} / \mathrm{L} \mathrm{MSG}$ and $1 \mathrm{~g} / \mathrm{L}$ D-glucose. Batch phase was performed at $75^{\circ} \mathrm{C}, \mathrm{pH} 3.1$, followed by a short fed-batch phase to increase the working volume to $2.0 \mathrm{~L}$. After reaching $2 \mathrm{~L}$ culture volume the vessel was operated in continuous mode by harvesting at the same rate as medium was being supplied via the substrate feed. To ensure the absence of time effects and to ensure reproducibility of the results, after performing a shift from low to high growth rate $\left(\mu=0.011-0.035 \mathrm{~h}^{-1}\right)$ we employed another phase of high dilution rate replicating the conditions of the initial phase $\left(\mu=0.035 \mathrm{~h}^{-1}\right)$. To ensure enough time for the organism to adapt to the different growth rates, sampling was performed at least 2 dwell times $(\sim 2.5$ days and $\sim 8$ days, respectively) after changing the dilution rate.

Per sampling point $45 \mathrm{~mL}$ aliquots were withdrawn and cells were harvested via centrifugation $\left(14,000 g, 4{ }^{\circ} \mathrm{C}\right.$, $10 \mathrm{~min})$. Sampling points and respective dry cell weights are shown in Table 1 . The cell pellet was then stored at $-20{ }^{\circ} \mathrm{C}$ for later use.

Dissolved oxygen $\left(\mathrm{dO}_{2}\right)$ was measured with a dissolved oxygen electrode Visiferm DO425 (Hamilton, USA) and $\mathrm{dO}_{2}$ levels were maintained above $30 \%$ by aerating with up to $0.6 \mathrm{~L} / \mathrm{min}$ pressurized air. $\mathrm{pH}$ was monitored with an Easyferm electrode (Hamilton, USA) and kept at 3.1 by addition of $\mathrm{H}_{2} \mathrm{SO}_{4}(9.6 \% \mathrm{v} / \mathrm{v})$ via the pump module of the bioreactor. Feed was supplied via a Preciflow peristaltic pump (Lambda, Switzerland) following a feed-forward controlled 
Table 1 End-conditions of the distinct phases of constant dilution rates

\begin{tabular}{llrlll}
\hline & $\begin{array}{l}\text { Time at } \\
\text { sampling }(\mathrm{h})\end{array}$ & $\begin{array}{l}\text { Phase dura- } \\
\text { tion }(\mathrm{h})\end{array}$ & $\begin{array}{l}\text { Dilution rate }(D) \text { and spe- } \\
\text { cific growth rate }(\mu)\left(\mathrm{h}^{-1}\right)\end{array}$ & $\begin{array}{l}\text { Dwell time } \\
(\tau)(\mathrm{h})\end{array}$ & $\begin{array}{l}\text { Dry cell } \\
\text { weight }(\mathrm{DCW}) \\
(\mathrm{g} / \mathrm{L})\end{array}$ \\
\hline Constant Phase 1 & 334.4 & 70.0 & 0.035 & 28.6 & $1.95 \pm 0.05$ \\
Constant Phase 2 & 527.3 & 192.9 & 0.011 & 90.9 & $2.11 \pm 0.12$ \\
Constant Phase 3 & 599.5 & 72.2 & 0.035 & 28.6 & $1.85 \pm 0.13$ \\
\hline
\end{tabular}

exponential feeding strategy, while broth was continuously withdrawn via a dip pipe and a Preciflow peristaltic pump (Lambda, Switzerland). Mixing was performed at $350 \mathrm{rpm}$. $\mathrm{CO}_{2}$ and $\mathrm{O}_{2}$ contents in the offgas were analyzed with $\mathrm{BCP}-$ $\mathrm{O}_{2}$ and $\mathrm{BCP}-\mathrm{CO}_{2}$ gas analyzers (Bluesens, Germany). Process parameters were adjusted and recorded via the process information management system Lucullus (Securecell, Switzerland).

\section{Biomass determination}

Dry cell weight, $D C W[\mathrm{~g} / \mathrm{L}]$, was determined gravimetrically in triplicates. $5 \mathrm{~mL}$ fermentation broth were centrifuged $\left(4000 \mathrm{~g}, 4{ }^{\circ} \mathrm{C}, 15 \mathrm{~min}\right)$ and subsequently dried at $95{ }^{\circ} \mathrm{C}$ for at least $72 \mathrm{~h}$.

Optical density, $O D_{600}$ [ ], was determined photometrically at $600 \mathrm{~nm}$. Samples were diluted with deionized water to stay in the linear range of the photometer (Genesys 20, Thermo Fisher Scientific, USA).

\section{Calculation of dilution rate, specific growth rate and dwell time}

Dilution rate, $D[1 / \mathrm{h}]$, in a CSTR was calculated as the quotient of volume flow $[\mathrm{L} / \mathrm{h}]$ by the reactor volume [L].

Specific growth rate, $\mu\left[\mathrm{h}^{-1}\right]$, in an equilibrated CSTR can be assumed equal to $D$. Therefore, during the experimental phases $\mu$ was controlled and set to 0.11 and $0.35 \mathrm{~h}^{-1}$, respectively, via the volume flow, which is proportional to the feed rate $[\mathrm{g} / \mathrm{h}]$, at a constant reactor volume.

Dwell time, $\tau[\mathrm{h}]$, was calculated as the reciprocal value of the dilution rate $D$.

\section{Lipid extraction}

Frozen cell pellets of $45 \mathrm{~mL}$ culture broth per sample (dry cell weight at the time of harvest is shown in Table 1) were thawed and resuspended in $5 \mathrm{~mL}$ ammonium acetate $(155 \mathrm{mM})$. After sonication on ice $(6 \times 1 \mathrm{~min}$ with $30 \mathrm{~s} \mathrm{cool-}$ ing periods between pulses, duty cycle $50 \%$, output control 7; Branson Sonifier 250, Thermo Fisher Scientific, USA) $20 \mathrm{~mL}$ of a chloroform/methanol solution $(2: 1 \mathrm{vol} / \mathrm{vol})$ was added. Lipids were extracted via vigorous shaking on a vibrating panel at $2200 \mathrm{rpm}$ (ika-vibrax-vxr Typ VX7,
Janke \& Kunkel, Germany) for $30 \mathrm{~min}$ at $4{ }^{\circ} \mathrm{C}$. For phase separation the mixture was centrifuged $\left(1000 \mathrm{~g}, 4^{\circ} \mathrm{C}, 2 \mathrm{~min}\right)$. Subsequently the lower organic phase was removed carefully and the solvent was evaporated to dryness under a nitrogen stream $(0.2 \mathrm{~L} / \mathrm{min})$ at room temperature. The remaining solid lipid extract was stored at $-20{ }^{\circ} \mathrm{C}$ for further analysis. All steps following the addition of chloroform/methanol were performed in glassware.

\section{Structural analysis of lipids}

All measurements were performed using a Shimadzu MALDI 7090 tandem time-of-flight (TOF) mass spectrometer (Shimadzu-Kratos Analytical, Manchester, UK) described in detail elsewhere (Belgacem et al. 2016). Briefly, the instrument is fitted with a frequency-tripled $2 \mathrm{kHz}$ Nd-YAG laser $(\lambda=355 \mathrm{~nm})$ operated for sensitivity reasons at $200 \mathrm{~Hz}$, a linear TOF analyzer as MS1 and a wide energy-acceptance curved field RTOF as MS2 for product ion analysis (close to $95 \%$ of the selected $\mathrm{m} / \mathrm{z}$ range), a grounded gas collision cell with differential pumping of the collision region, a double Bradbury-Nielsen wire ion gate for precursor ion selection, an axial spatial distribution focusing (ASDF) lens for obtaining product ion resolutions up to 10,000 (FWHH) and two secondary electron multipliers for linear and reflectron TOF-MS, respectively, for ion detection.

All archaeal lipid samples were dissolved at roughly $1 \mathrm{mg}$ per $1000 \mu \mathrm{L}$ solvent (methanol:chloroform $=7: 3 \mathrm{vol} / \mathrm{vol}$ ). 2, 4, 6-Trihydroxyacetophenone was selected as MALDImatrix for all experiments (positive- and negative-ion detection) by dissolving $15 \mathrm{mg}$ matrix in $1000 \mu \mathrm{L}$ methanol. Alternatively, the matrix solution was saturated with sodium chloride to improve mono- and disodiated molecules for positive-ion detection. For final sample preparation, analyte solution and matrix solution were mixed 1:1 ( $\mathrm{vol} / \mathrm{vol})$ immediately before applying $1 \mu \mathrm{L}$ of the resulting mixture onto the standard stainless steel target surface (dried droplet preparation).

All displayed positive- as well as negative-ion mass spectra represent an average of 10,000 unselected mass spectra (1 mass spectrum represents the average of 5 individual laser pulses). This number of shots was acquired in order to obtain satisfactory ion statistics across the mass range selected. 


\section{Results and discussion}

\section{Bioreactor cultivation}

Figure 1 shows the time course of the $\mathrm{CO}_{2}$ signal in the offgas which corresponds to the metabolic activity of the culture and the course of DCW which converges towards its equilibrium state. Dilution rate, calculated as the quotient of the feedrate by the reactor volume, is also shown in Fig. 1. DCW, $\mu$, and $\tau$ at the end of each phase of constant $D$, as well as phase duration, are shown in Table 1. Owing to the increased dilution, the DCW is lower in the phases of higher $\mu(1.9$ vs $2.1 \mathrm{~g} / \mathrm{L})$.

\section{Lipid composition and structure}

In brief, like characteristic for members of the phylum Crenarchaeota, the lipids of Sulfolobus species consist of an isoprenoid core structure either in form of two diterpenoides or two tetraterpenoides connected with one or two glycerols, respectively, via ether bonds in the $s n-2,3$ positions. Polar head groups are connected in the $s n-1$ position and commonly consist of (poly-) hexoses (Hex), inositolphosphate (IP) or sulfonated trihexose (sulfono-Hex3). In the literature "archaeol", "diether lipid" (DEL) or more specifically "dialkyl glycerol diether" (DGD) is common term for the diterpenoide containing $\mathrm{C}_{40}$ core structures, while the tetraterpenoide containing $\mathrm{C}_{80}$ core structures are known as "caldarchaeol", "tetraether lipid" (TEL) or, more specifically, "glycerol dialkyl glycerol tetraether" (GDGT). These lipid classes which can be distinguished based on their lipid core and head groups can be further divided into lipid species. The latter describe lipids with the same head groups and number of carbon atoms, but with different number of cylopentane moieties. In this study for the notation of the lipid classes we follow the nomenclature described by Jensen et al. (2015a), using the terms DGD and GDGT for the description of the core structures preceded or followed with the above described abbreviations for the polar head groups. The chemical structures of the most abundant lipid classes found in this study are shown in the supplementary material.

Relative quantification of the lipid classes was performed based on peak height in the full scan mass spectra acquired in positive mode with $\mathrm{NaCl}$ spiking. Spiking with a surplus of $\mathrm{NaCl}$ guarantees uniform desorption/ionization of lipids and allows the detection of neutral lipids (Pittenauer and Allmaier 2009). For the comparison of the abundances we focused on the most abundant peaks in the lipid mass spectrum, exemplarily shown in Fig. 2. These were identified as the lipid classes Hex2-GDGT, IP-DGD, GDGT, IP-GDGT and Hex2-GDGT-IP.

The most abundant lipid class observed in S. acidocaldarius was Hex2-GDGT. Independent of the growth rate $58 \%$ of the total amount of lipids were Hex2-GDGT. As second most abundant class followed the diether IP-DGD with its share being highly dependent on the employed growth rate ( $25 \%$ at $\mu=0.011 \mathrm{~h}^{-1}$ and $16 \%$ at $\mu=0.035 \mathrm{~h}^{-1}$ ). IP-DGD was the only class of DELs that we found in significant amounts. GDGT, IP-GDGT and Hex2-GDGT-IP were present in amounts of $3-11 \%$ of total lipids. While the abundance of GDGT decreased from 9 to $7 \%$ when $\mu$ was increased, classes containing inositol phosphate were considerably more abundant at the higher $\mu\left(4 \%\right.$ at $\mu=0.011 \mathrm{~h}^{-1}$
Fig. 1 Continuous cultivation of $S$. acidocaldarius in a 3.6-L bioreactor $(2.0 \mathrm{~L}$ working volume). Samples for determination of the lipid composition were drawn at the end of phases of constant dilution rate at the indicated time points 1,2 and 3 (where 1 and 3 are replicates of the same biological state). Dry cell weight (DCW) [filled square], $\mathrm{CO}_{2}$ concentration [dashed line] and dilution rate (D) [horizontal line] are shown

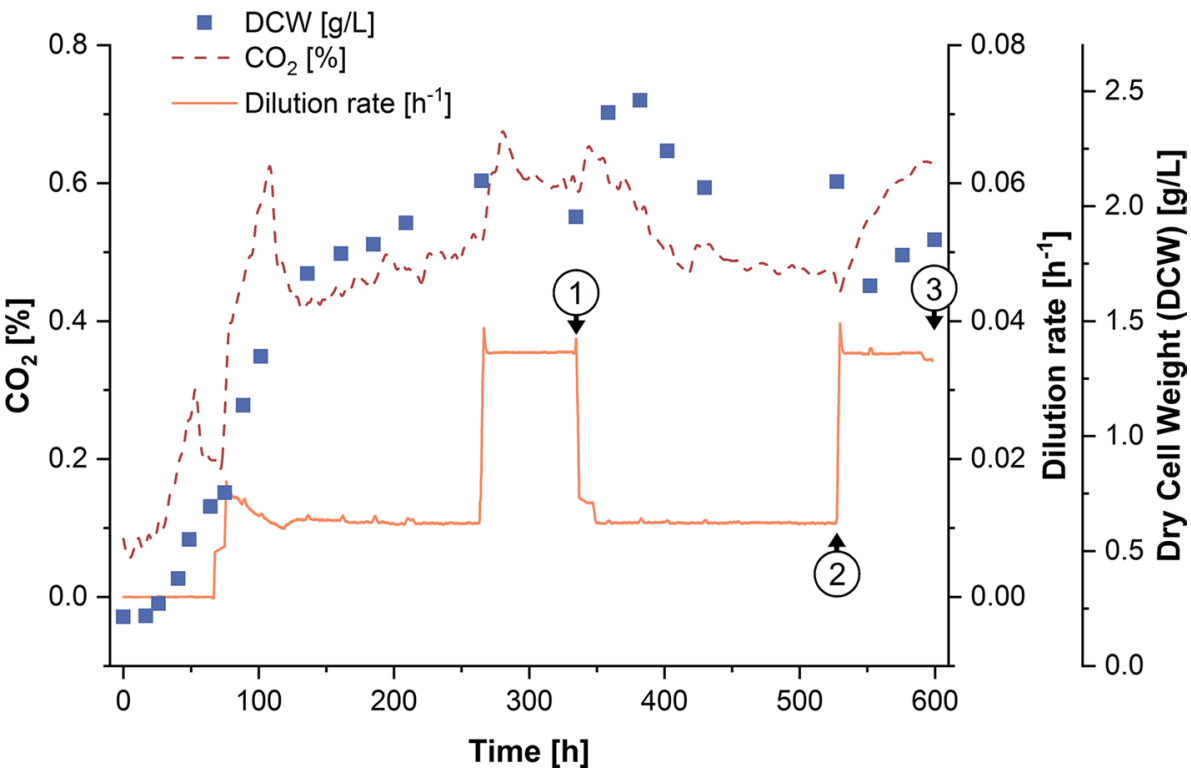




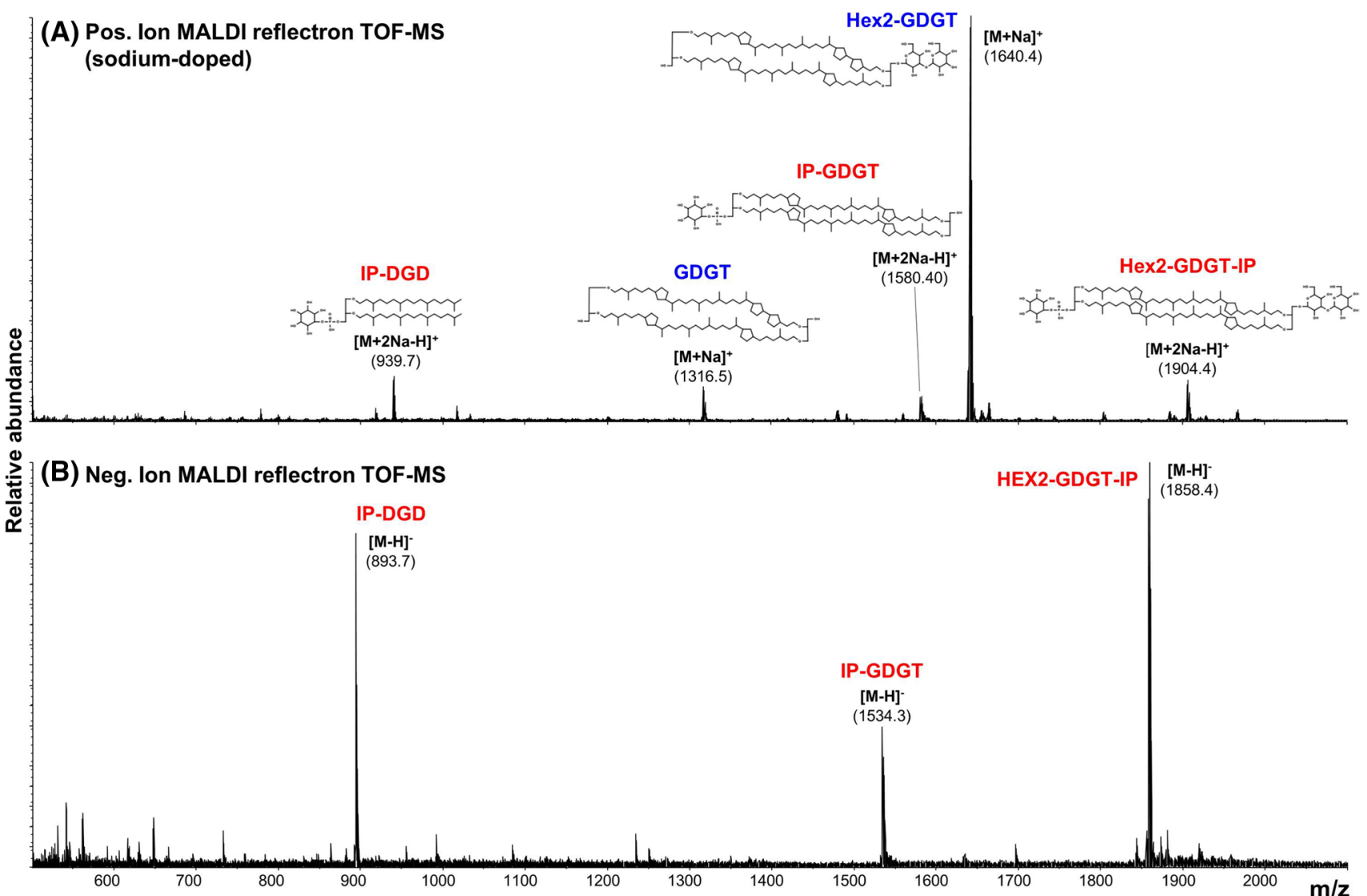

Fig. 2 a Positive-ion MALDI reflectron TOF-MS spectrum of a $S$. acidocaldarius lipid extract spiked with $\mathrm{NaCl}$. The spectrum shows the five most abundant lipid species in $S$. acidocaldarius. $\mathrm{m} / z$ values and structure of the dominant lipid species are given. b Negative-ion
MALDI reflectron TOF-MS spectrum of the same sample. Noteworthy, in the negative-ion mode phosphate-free lipids (highlighted in blue in Fig. 2a) cannot be detected

lipid composition. Based on 16S rDNA analysis S. acidocaldarius is phylogenetically more closely related to $S$. tokodaii (Quehenberger et al. 2017), while it is more similar to $S$. islandicus in regards to optimal growth temperature $\left(75^{\circ} \mathrm{C}\right.$ for S. acidocaldarius and S. islandicus (Zhang et al. 2013) vs. $80^{\circ} \mathrm{C}$ for $S$. tokodaii (Suzuki et al. 2002)). Table 2 shows the key indicators of the lipid composition which we will compare to the results of Jensen et al. (2015b) in the following paragraphs.

\section{Abundance of different lipid classes}

The results of the present study and the study by Jensen et al. are similar, with Hex2-GDGT-IP, IP-GDGT and IP-DGD being identified as major lipid classes in both studies. Additionally, we identified significant amounts of Hex2-GDGT or Hex-GDNT, two compounds that we were not able to distinguish with the used MS method. Jensen et al. also found significant amounts of sulfono-Hex3-GDGT-IP, while we detected this lipid class only in minor quantities in our samples. Possibly, this is a result of a sample preparation or caldarius that were investigated in terms of their membrane 
Fig. 3 a Distribution of the major lipid classes in S. acidocaldarius in dependence of the growth rate $(\mu)$. Measurements were taken in positive MS mode with addition of $\mathrm{NaCl}$. Values are given as \% of the sum of major lipid classes. b Distribution of cyclopentane rings and average cyclization number in the investigated GDGT classes of $S$. acidocaldarius in dependence of $\mu$. Errors indicated for the blue bars represent the divergence between the replicates of the two biological states (1 and 3 ) as shown in Fig. 1
Table 2 Overview of key indicators of the lipid composition identified in this study
(A)

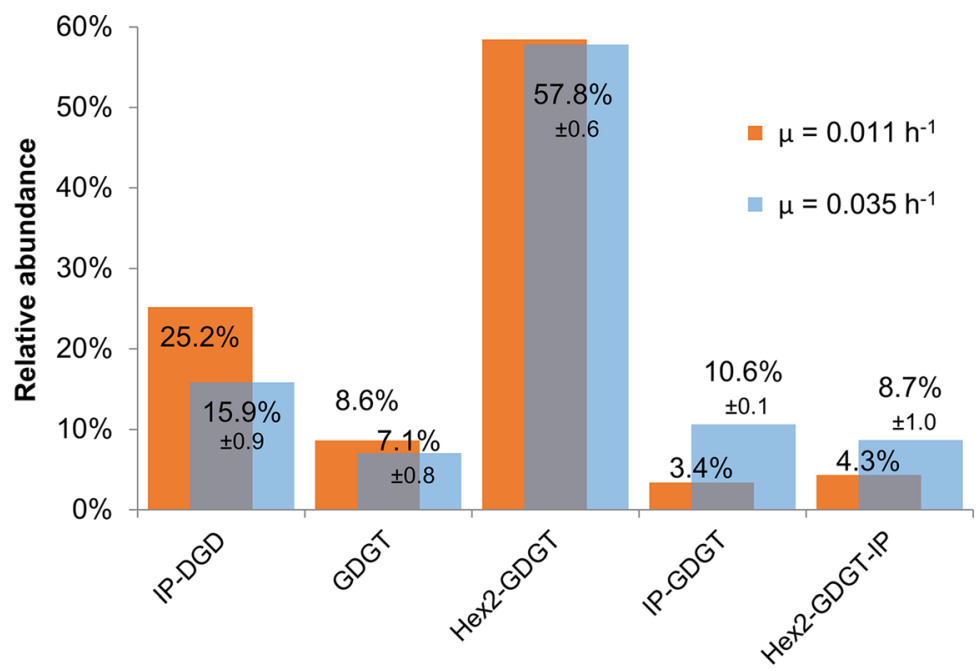

(B)

\begin{tabular}{|c|c|c|c|c|c|c|c|c|}
\hline \multirow{2}{*}{$\begin{array}{c}\text { Cyclo- } \\
\text { pentane } \\
\text { moieties }\end{array}$} & \multicolumn{4}{|c|}{$\mu=0.011 h^{-1}$} & \multicolumn{4}{|c|}{$\mu=0.035 h^{-1}$} \\
\hline & GDGT & $\begin{array}{l}\text { Hex2- } \\
\text { GDGT }\end{array}$ & IP-GDGT & $\begin{array}{l}\text { Hex2- } \\
\text { GDGT-IP }\end{array}$ & GDGT & $\begin{array}{l}\text { Hex2- } \\
\text { GDGT }\end{array}$ & IP-GDGT & $\begin{array}{l}\text { Hex2- } \\
\text { GDGT-IP }\end{array}$ \\
\hline 7 & - & - & - & $4 \%$ & - & - & - & $\beta \% \pm 0.7$ \\
\hline 6 & $48 \%$ & $63 \%$ & $19 \%$ & $28 \%$ & $23 \% \pm 2.3$ & $28 \% \pm 2.5$ & $5 \% \pm 1.1$ & $9 \% \pm 4.1$ \\
\hline 5 & $36 \%$ & $29 \%$ & $43 \%$ & $34 \%$ & $49 \% \pm 0.5$ & $54 \% \pm 0.3$ & $34 \% \pm 0.6$ & $10 \% \pm 0.6$ \\
\hline 4 & $16 \%$ & $8 \%$ & $26 \%$ & $23 \%$ & $28 \% \pm 2.8$ & $18 \% \pm 2.8$ & $57 \% \pm 0.6$ & $35 \% \pm 0.5$ \\
\hline 3 & - & - & $12 \%$ & $11 \%$ & - & - & $4 \% \pm 0.1$ & $43 \% \pm 4.9$ \\
\hline $\begin{array}{c}\text { Average } \\
\text { cyclization } \\
\text { number }\end{array}$ & 5.3 & 5.6 & 4.7 & 4.9 & 5.0 & 5.1 & 4.4 & 3.9 \\
\hline
\end{tabular}

measurement bias, causing an over- or underestimation of the compound. Also the fact that we investigated the lipid composition using positive-ion mode has an influence on the detected lipid pattern, since neutral lipids are easily overlooked when only negative-ion mode mass spectra are considered (see Fig. 2).

\section{Ratio of DEL:TEL among the different Sulfolobus species}

Jensen et al. found DEL:TEL ratios in the exponential phase of $1: 8$ and $1: 5$ for $S$. islandicus $\left(75^{\circ} \mathrm{C}\right)$ and $S$. tokodaii $\left(80{ }^{\circ} \mathrm{C}\right)$, respectively. For the lag phase ratios of $1: 3$ and 1:2 were calculated. It should be noted that the ratios calculated in the study of Jensen et al. are strongly fluctuating with culture conditions and oftentimes it is hard to find a clear trend or pattern in the DEL:TEL ratios. Based on our results, the DEL:TEL ratio of $S$. acidocaldarius at $75{ }^{\circ} \mathrm{C}$ is 1:3 for the lower $\mu$ of $0.011 \mathrm{~h}^{-1}$ and 1:5.5 for the higher $\mu$ of $0.035 \mathrm{~h}^{-1}$. These values lie within the ratios determined for the two related species.

\section{Number of cyclopentane moieties}

According to the results of Jensen et al. when grown at the same temperature the lipids of $S$. islandicus have, on average, approximately one ring less compared to $S$. tokodaii ( 4 vs. 5 rings). A temperature shift of $5{ }^{\circ} \mathrm{C}$ results in a difference of $\sim 0.5$ rings for both species and since the optimal growth temperature of $S$. islandicus is $5{ }^{\circ} \mathrm{C}$ lower than for $S$. tokodaii, the two species actually differ by $\sim 1.5$ cyclopentane rings during the exponential phase at their respective optimal growth conditions. For S. acidocaldarius we found 
the average number of rings for the higher growth rate to be 4.6 at the optimal growth temperature of $75^{\circ} \mathrm{C}$.

\section{Effect of growth phase/growth rate}

Jensen et al. showed for both organisms that the ring number dropped during the exponential phase and rose again in the stationary phase. They hypothesized that rather than the growth phase the specific growth rate might be the reason for the change in the lipid pattern. Indeed, while the correlation between average cyclization number and calculated growth rate was rather low for S. islandicus (0.43-0.15), in the case of $S$. tokodaii they observed a very high correlation $(\geq-0.97)$. We found the same relationship for $S$. acidocaldarius. Jensen et al. "suspected the reason behind the observation in a lacking speed of lipid cyclization during biosynthesis at high growth rates". Interestingly, in all three Sulfolobus species the number of rings decreases at the higher growth rate, while at the same time the share of TELs increases. A possible explanation for this behavior is that caused by the lack of nutrients the organism produces the chemically simpler archaeoles at the expense of the much more complex cyclopentane ring-bearing caldarchaeols (Jain et al. 2014; Villanueva et al. 2014). Subsequently, more cyclopentane rings are incorporated per remaining molecule of caldarchaeol.

\section{Conclusion}

The lipid membrane of Archaea is a flexible and highly adaptive system. In this study we show that for the Crenarchaeum $S$. acidocaldarius this flexibility is not only a reaction of homeoviscous adaption to compensate for environmental factors, like shifts in $\mathrm{pH}$ or temperature, in order to maintain a constant state of membrane fluidity. Rather, $S$. acidocaldarius reacts with a change in the lipid composition to cope with nutrient limitation. The initial hypothesis maintains that $S$. acidocaldarius reacts to changes in $\mu$ with a change in its lipid pattern. More precisely, at a higher $\mu$ the share of IP-GDGT and Hex2-GDGT-IP increases at the expense of IP-DGD, while the average number of cyclopentane rings decreases. Since this study was performed in equilibrated cultivation conditions, these changes in the lipid pattern are truly consequences of a different growth rate and also happen in absence of the influence of different physiological states, as present in case of lag, exponential and stationary phase.

Summarizing, in this study we identified a novel factor (the controlled specific growth rate) for influencing the lipid composition of $S$. acidocaldarius. We were able to determine the effect of this factor on the lipid composition for the first time using MALDI-MS for the semi-quantification of an archaeal lipidome. A shift in the specific growth rate during a controlled continuous cultivation of $S$. acidocaldarius led to a change in the ratio of diether to tetraether lipids and in the average number of cyclopentane rings. Limitation of the growth rate led to an increase of the share of diethers, while the remaining tetraether lipids featured a higher average cyclization number.

Acknowledgements Open access funding provided by TU Wien (TUW).

Author contributions OS and GA conceived the idea for this study. JQ designed and performed the experiments for cultivation of $S$. acidocaldarius and lipid extraction. EP performed lipid analysis and evaluation of mass spectrometric data. The first draft of the manuscript was written by JQ and all authors commented on previous versions of the manuscript. All authors read and approved the final manuscript.

Funding The authors received no specific funding for this work.

\section{Compliance with ethical standards}

Conflict of interest The authors declare that they have no known competing financial interests or personal relationships that could have influenced the work reported in this paper.

Open Access This article is licensed under a Creative Commons Attribution 4.0 International License, which permits use, sharing, adaptation, distribution and reproduction in any medium or format, as long as you give appropriate credit to the original author(s) and the source, provide a link to the Creative Commons licence, and indicate if changes were made. The images or other third party material in this article are included in the article's Creative Commons licence, unless indicated otherwise in a credit line to the material. If material is not included in the article's Creative Commons licence and your intended use is not permitted by statutory regulation or exceeds the permitted use, you will need to obtain permission directly from the copyright holder. To view a copy of this licence, visit http://creativecommons.org/licenses/by/4.0/.

\section{References}

Belgacem O, Pittenauer E, Openshaw ME, Hart PJ, Bowdler A, Allmaier G (2016) Axial spatial distribution focusing: improving MALDI-TOF/RTOF mass spectrometric performance for highenergy collision-induced dissociation of biomolecules. Rapid Commun Mass Spectrom 30:343-351. https://doi.org/10.1002/ $\mathrm{rcm} .7458$

Bischof LF, Haurat MF, Hoffmann L, Albersmeier A, Wolf J, Neu A et al (2019) Early response of Sulfolobus acidocaldarius to nutrient limitation. Front Microbiol. https://doi.org/10.3389/fmicb .2018 .03201

Chong PL-G (2010) Archaebacterial bipolar tetraether lipids: physicochemical and membrane properties. Chem Phys Lipid 163:253265. https://doi.org/10.1016/j.chemphyslip.2009.12.006

Damsté JSS, Schouten S, Hopmans EC, van Duin ACT, Geenevasen JAJ (2002) Crenarchaeol the characteristic core glycerol dibiphytanyl glycerol tetraether membrane lipid of cosmopolitan pelagic crenarchaeota. J Lipid Res 43:1641-1651. https://doi. org/10.1194/jlr.M200148-JLR200 
Damsté JSS, Rijpstra WIC, Hopmans EC, den Uijl MJ, Weijers JWH, Schouten S (2018) The enigmatic structure of the crenarchaeol isomer. Org Geochem 124:22-28. https://doi.org/10.1016/j.orgge ochem.2018.06.005

Dawson KS, Freeman KH, Macalady JL (2012) Molecular characterization of core lipids from halophilic archaea grown under different salinity conditions. Org Geochem 48:1-8. https://doi. org/10.1016/j.orggeochem.2012.04.003

De Rosa M, Gambacorta A (1988) The lipids of archaebacteria. Prog Lipid Res 27:153-175. https://doi.org/10.1016/01637827(88)90011-2

De Rosa M, Esposito E, Gambacorta A, Nicolaus B, BuLock JD (1980) Effects of temperature on ether lipid composition of $\mathrm{Cal}$ dariella acidophila. Phytochemistry 19:827-831. https://doi. org/10.1016/0031-9422(80)85120-X

Elling FJ, Könneke M, Lipp JS, Becker KW, Gagen EJ, Hinrichs K-U (2014) Effects of growth phase on the membrane lipid composition of the thaumarchaeon Nitrosopumilus maritimus and their implications for archaeal lipid distributions in the marine environment. Geochim Cosmochim Acta 141:579-597. https://doi. org/10.1016/j.gca.2014.07.005

Guan Z, Delago A, Nußbaum P, Meyer BH, Albers S-V, Eichler J (2017) Gene deletions leading to a reduction in the number of cyclopentane rings in Sulfolobus acidocaldarius tetraether lipids. FEMS Microbiol Lett. https://doi.org/10.1093/femsle/fnx250

Jain S, Caforio A, Driessen AJM (2014) Biosynthesis of archaeal membrane ether lipids. Front Microbiol. https://doi.org/10.3389/fmicb .2014 .00641

Jensen SM, Brandl M, Treusch AH, Ejsing CS (2015a) Structural characterization of ether lipids from the archaeon Sulfolobus islandicus by high-resolution shotgun lipidomics. J Mass Spectrom 50:476-487. https://doi.org/10.1002/jms.3553

Jensen SM, Neesgaard VL, Skjoldbjerg SLN, Brandl M, Ejsing CS, Treusch AH (2015b) The effects of temperature and growth phase on the lipidomes of Sulfolobusislandicus and Sulfolobustokodaii. Life 5:1539-1566. https://doi.org/10.3390/life5031539

Kaneshiro SM, Clark DS (1995) Pressure effects on the composition and thermal behavior of lipids from the deep-sea thermophile Methanococcus jannaschii. J Bacteriol 177:3668-3672. https:// doi.org/10.1128/jb.177.13.3668-3672.1995

Knappy CS, Chong JPJ, Keely BJ (2009) Rapid discrimination of archaeal tetraether lipid cores by liquid chromatography-tandem mass spectrometry. J Am Soc Mass Spectrom 20:51-59. https:// doi.org/10.1016/j.jasms.2008.09.015

Koga Y, Morii H (2007) Biosynthesis of ether-type polar lipids in archaea and evolutionary considerations. Microbiol Mol Biol Rev 71:97-120. https://doi.org/10.1128/MMBR.00033-06

Kramer JKG, Sauer FD (1991) Changes in the diether-to-tetraetherlipid ratio during cell growth in Methanobacterium thermoautotrophicum. FEMS Microbiol Lett 83:45-50. https://doi. org/10.1111/j.1574-6968.1991.tb04386.x

Lai D, Springstead JR, Monbouquette HG (2008) Effect of growth temperature on ether lipid biochemistry in Archaeoglobus fulgidus. Extremophiles 12:271-278. https://doi.org/10.1007/s0079 2-007-0126-6

Matsuno Y, Sugai A, Higashibata H, Fukuda W, Ueda K, Uda I et al (2009) Effect of growth temperature and growth phase on the lipid composition of the archaeal membrane from Thermococcus kodakaraensis. Biosci Biotechnol Biochem 73:104-108. https:// doi.org/10.1271/bbb. 80520
Meador TB, Gagen EJ, Loscar ME, Goldhammer T, Yoshinaga MY, Wendt $\mathbf{J}$ et al (2014) Thermococcus kodakarensis modulates its polar membrane lipids and elemental composition according to growth stage and phosphate availability. Front Microbiol. https:// doi.org/10.3389/fmicb.2014.00010

Morii H, Koga Y (1993) Tetraether type polar lipids increase after logarithmic growth phase of Methanobacterium thermoautotrophicum in compensation for the decrease of diether lipids. FEMS Microbiol Lett 109:283-287. https://doi.org/10.1111/j.1574-6968.1993. tb06182.x

Morii H, Eguchi T, Nishihara M, Kakinuma K, König H, Koga Y (1998) A novel ether core lipid with H-shaped C80-isoprenoid hydrocarbon chain from the hyperthermophilic methanogen Methanothermus fervidus. Biochim Biophys Acta-Lipids Lipid Metab 1390:339-345. https://doi.org/10.1016/S0005-2760(97)00183-5

Oger PM, Cario A (2013) Adaptation of the membrane in Archaea. Biophys Chem 183:42-56. https://doi.org/10.1016/j.bpc.2013.06.020

Pittenauer E, Allmaier G (2009) The renaissance of high-energy CID for structural elucidation of complex lipids: MALDI-TOF/RTOFMS of alkali cationized triacylglycerols. J Am Soc Mass Spectrom 20:1037-1047. https://doi.org/10.1016/j.jasms.2009.01.009

Quehenberger J, Shen L, Albers S-V, Siebers B, Spadiut O (2017) Sulfolobus - a potential key organism in future biotechnology. Front Microbiol. https://doi.org/10.3389/fmicb.2017.02474

Quehenberger J, Albersmeier A, Glatzel H, Hackl M, Kalinowski J, Spadiut O (2019) A defined cultivation medium for Sulfolobus acidocaldarius. J Biotechnol 301:56-67. https://doi.org/10.1016/j. jbiotec.2019.04.028

Shimada H, Nemoto N, Shida Y, Oshima T, Yamagishi A (2008) Effects of $\mathrm{pH}$ and temperature on the composition of polar lipids in Thermoplasma acidophilum HO-62. J Bacteriol 190:54045411. https://doi.org/10.1128/JB.00415-08

Suzuki T, Iwasaki T, Uzawa T, Hara K, Nemoto N, Kon T et al (2002) Sulfolobus tokodaii sp. nov. (f. Sulfolobus sp. strain 7), a new member of the genus Sulfolobus isolated from Beppu Hot Springs Japan. Extremophiles 6:39-44. https://doi.org/10.1007/s0079 20100221

van de Vossenberg JLCM, Driessen AJM, Konings WN (1998) The essence of being extremophilic: the role of the unique archaeal membrane lipids. Extremophiles 2:163-170. https://doi. org/10.1007/s007920050056

Villanueva L, Damsté JSS, Schouten S (2014) A re-evaluation of the archaeal membrane lipid biosynthetic pathway. Nat Rev Microbiol 12:438-448. https://doi.org/10.1038/nrmicro3260

Yoshinaga MY, Gagen EJ, Wörmer L, Broda NK, Meador TB, Wendt J et al (2015) Methanothermobacter thermautotrophicus modulates its membrane lipids in response to hydrogen and nutrient availability. Front Microbiol. https://doi.org/10.3389/fmicb.2015.00005

Zhang C, Cooper TE, Krause DJ, Whitaker RJ (2013) Augmenting the genetic toolbox for Sulfolobus islandicus with a stringent positive selectable marker for agmatine prototrophy. Appl Environ Microbiol 79:5539-5549. https://doi.org/10.1128/AEM.01608-13

Publisher's Note Springer Nature remains neutral with regard to jurisdictional claims in published maps and institutional affiliations. 